\title{
Regional anesthesia in Canadian emergency departments: Emergency physician practices, perspectives, and barriers to use
}

\author{
David Wiercigroch, MPA*; Maxim Ben-Yakov, $\mathrm{MDCM}^{\dagger}$; Danielle Porplycia, $\mathrm{MSc}^{\dagger}$; \\ Steven Marc Friedman, MD, $\mathrm{MPH}^{\dagger}$
}

\section{CLINICIAN'S CAPSULE}

What is known about the topic?

Regional anesthesia in the emergency department (ED) is associated with reduced opioid dosing and related side effects.

What did this study ask?

We characterized the use of regional anesthesia by Canadian emergency physicians, including practices, perspectives, and barriers.

What did this study find?

Emergency physicians express interest in expanding their use of regional anesthesia and improving its integration into ED workflow.

Why does this study matter to clinicians?

Additional training, protocols, and support from nursing staff are modifiable factors that could facilitate uptake in the ED.

\section{ABSTRACT}

Objectives: Regional anesthesia has many applications in the emergency department (ED). It has been shown to reduce general anesthetic dose, requirement for post-procedural opioids, and recovery time. We sought to characterize the use of regional anesthesia by Canadian emergency physicians, including practices, perspectives and barriers to use in the ED. Methods: A cross-sectional survey was administered to members of the Canadian Association of Emergency Physicians (CAEP), consisting of sixteen multiple choice and numerical response questions. Responses were summarized descriptively as percentages and as the median and inter quartile range (IQR) for quantitative variables.

Results: The survey was completed by $149 / 1144$ staff emergency physicians, with a response rate of $13 \%$. Respondents used regional anesthesia a median of 2 (IOR $0-4)$ times in the past ten shifts. The most broadly used applications were soft tissue repair $(84.5 \%$ of respondents, $n=126)$, fracture pain management $(79.2 \%, n=118)$ and orthopedic reduction $(72.5 \%$, $\mathrm{n}=108$ ). Respondents agreed that regional anesthesia is safe to use in the ED (98.7\%) and were interested in using it more frequently $(78.5 \%)$. Almost all $(98.0 \%)$ respondents had point of care ultrasound available, however less than half $(49.0 \%)$ felt comfortable using it for RA. Respondents indicated that they required more training (76.5\%), a departmental protocol $(47.0 \%)$, and nursing assistance $(30.2 \%)$ to increase their use of RA.

Conclusion: Canadian emergency physicians use regional anesthesia infrequently but express an interest in expanding their use. While equipment is available, additional training, protocols, and increased support from nursing staff are modifiable factors that could facilitate uptake.

\section{RÉSUMÉ}

Objectif: L'anesthésie locorégionale (ALR) compte de nombreuses applications au service des urgences (SU). II a été démontré qu'elle permettait de réduire la dose d'anesthésique général, la prise d'opioïdes en phase postopératoire et le temps de réveil. Aussi l'étude visait-elle à caractériser le recours à l'anesthésie locorégionale au SU, au Canada, notamment les pratiques des médecins en la matière, leurs points de vue et les obstacles à son application.

Méthode: Il s'agit d'une enquête transversale menée parmi les membres de l'Association canadienne des médecins d'urgence, à l'aide d'un questionnaire à choix multiple, en 16 points et à réponse numérique. Résumées à l'aide de statistiques descriptives, les réponses sont présentées sous forme de pourcentages ainsi que de médianes et d'intervalles interquartiles (IIQ) en ce qui concerne les variables quantitatives. Résultats: Au total, 149/1144 médecins membres du personnel d'urgence ont participé à l'enquête, soit un taux de réponse de

From ${ }^{*}$ Faculty of Medicine, University of Toronto, Toronto, ON, Canada; and the ${ }^{\dagger}$ University Health Network, Department of Emergency Medicine, Toronto, ON, Canada.

Correspondence to: Dr. Steven Marc Friedman, Department of Emergency Medicine, Toronto Western Hospital, 399 Bathurst St. Toronto, ON; Email: steven.friedman@utoronto.ca 
$13 \%$. D'après les répondants, le nombre médian de fois où ils ont eu recours à l'anesthésie locorégionale au cours des 10 derniers postes de travail était de 2 (IIQ : 0-4). Les applications les plus courantes concernaient les réparations de tissu mou (84,5\% des répondants; $n=126$ ), le soulagement de la douleur dans les cas de fracture $(79,2 \% ; n=118)$ et les réductions orthopédiques $(72,5 \% ; n=108)$. Les médecins étaient d'accord sur le fait que l'anesthésie locorégionale est une pratique sûre au SU $(98,7 \%)$ et ils ont manifesté de l'intérêt pour l'élargissement de son application (78,5\%). La quasi-totalité des participants $(98,0 \%)$ a déclaré disposer de l'échographie au chevet, mais moins de la moitié $(49,0 \%)$ se sentait à l'aise dans son utilisation aux fins de l'ALR. Enfin, les répondants ont indiqué que, pour accroître leur recours à I'ALR, ils auraient besoin davantage de formation $(76,5 \%)$, de protocoles d'application dans leur service $(47,0 \%)$ et du soutien du personnel infirmier (30,2\%).

Conclusion: Les médecins d'urgence au Canada pratiquent peu l'anesthésie locorégionale, mais ils ont manifesté de l'intérêt pour en accroître I'utilisation. Certes, ils disposent du matériel nécessaire mais, pour faciliter le recours à I'ALR, ils auraient besoin d'une formation approfondie, de protocoles d'application et d'un soutien accru du personnel infirmier, tous des facteurs modifiables.

Keywords: Nerve blocks, pain management, regional anesthesia

\section{INTRODUCTION}

Regional anesthesia, also referred to by the term "nerve block," has a broad range of applications in the emergency department (ED). ${ }^{1}$ Expanding expertise in ED point-of-care ultrasound (POCUS) decreases the risk of complications from regional anesthesia and has facilitated its use. ${ }^{1}$ Clinical trials of regional anesthesia, particularly ultrasound guided, demonstrate increased patient satisfaction, decreased ED length of stay, lower opioid requirements, and fewer opioid adverse effects. ${ }^{2,3}$

There is growing recognition of the importance of ultrasound-guided regional anesthesia in the ED. In 2017, more than one-half of the curriculum working group of the Canadian Association of Emergency Physicians (CAEP) emergency ultrasound committee believed that nerve blockade should be part of the core emergency ultrasound curriculum. ${ }^{4}$ In the United States, a recent study demonstrated consensus amongst ultrasound program directors on the importance of training in regional anesthesia. ${ }^{5}$

We sought to characterize the use of regional anesthesia and ultrasound-guided regional anesthesia by Canadian emergency physicians, perspectives, and barriers to use, as well as perceived requirements for greater uptake of this technique in the ED.

\section{METHODS}

\section{Study design}

This was a cross-sectional survey comprising multiple choice and numerical response questions. The design was informed by a review of previous surveys ${ }^{5,6}$ and in discussion with content experts. We piloted the survey among five academic emergency physicians who were closely matched to the study sample, for content validity and readability, and revised accordingly.

\section{Study setting and sampling}

Members of the CAEP who had not previously opted out of receiving research surveys were emailed an invitation to participate and a link to a web-based survey. We sent invitations at three biweekly intervals between May and June 2019 and administered the survey through SurveyMonkey. No incentive was provided for participation. The study was approved by the University Health Network (Toronto, ON) Research Ethics Board.

\section{Data analysis}

We used SPSS (version 25.0) to complete the data analysis. We summarized data using descriptive statistics. We reported survey responses as percentages of total respondents. For some questions, we combined similar categories to simplify the presentation of results. For example, survey responses "agree" and "somewhat agree" were summarized as "agree."

\section{RESULTS}

\section{Demographics}

The survey was emailed to 1,435 CAEP members. We excluded responses from medical students and 


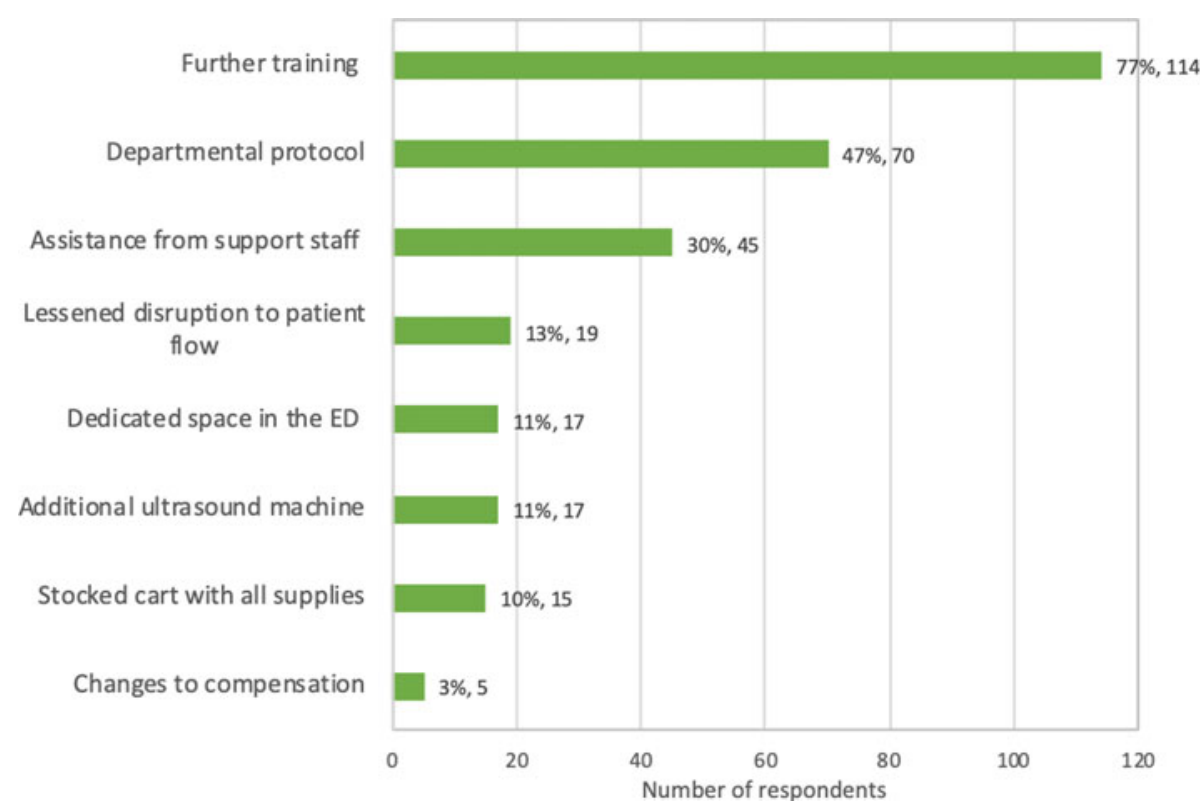

Figure 1. Resources required to increase regional anesthesia use in the $\operatorname{ED}(\%, n)$.

postgraduate trainees. The response rate was $13 \%(\mathrm{n}=$ 149 completed surveys out of 1,144 practising emergency physicians). Respondents varied across years in practice with $30.2 \%$ in their first 10 years of practice, $31.6 \%$ between 10 and 20 years in practice, and $38.3 \%$ over 20 years in practice. Academic centres comprised one-half $(49.7 \%)$ of practice settings, followed by community hospitals (39.7\%) and rural hospitals (10.7\%). Full demographic information is provided in Table 1 (Appendix).

\section{Current use of regional anesthesia and perspectives}

The frequency of regional anesthesia use in the ED ranged from 0 to 20 times in the past 10 shifts with a median frequency of two nerve blocks in the past 10 shifts (interquartile range $[\mathrm{IQR}] 0-4$ times in the past 10 shifts) (see Figure A1 in Appendix). The most commonly performed nerve blocks were digital $(90.6 \%, \mathrm{n}=135)$, hematoma block for wrist fracture $(75.8 \%, \mathrm{n}=113)$, nerve blocks of the face and mouth $(69.1 \%, \mathrm{n}=103)$, and dental blocks $(65.1 \%, \mathrm{n}=97)$ A complete list of nerve blocks performed and common indications for regional anesthesia use are reported in the Appendix (Figure A1 and A2).

A majority $(78.5 \%, \mathrm{n}=117)$ of respondents were interested in using regional anesthesia more frequently in the ED. Respondents agreed that regional anesthesia is safe to use in the $\operatorname{ED}(98.7 \%, \mathrm{n}=147)$, reduces the need for procedural sedation $(91.9 \%, \mathrm{n}=137)$, reduces the need for opioids $(90.6 \%, \mathrm{n}=135)$, and improves patient satisfaction $(66.4 \%, \mathrm{n}=99)$ (Figure A3 in Appendix).

\section{Barriers and facilitators of regional anesthesia use}

Almost all $(98 \%, \mathrm{n}=146)$ respondents had POCUS available to assist in performing nerve blocks, and most $(78.5 \%, \mathrm{n}=117)$ agreed that they had adequate equipment for regional anesthesia. More than one-half of respondents found nerve blocks to be time consuming $(63.8 \%, \mathrm{n}=95)$ and technically challenging $(59.7 \%$, $\mathrm{n}=89)$. Only $49.0 \%(\mathrm{n}=73)$ felt comfortable using POCUS to perform nerve blocks. Most respondents did not have a protocol in place for regional anesthesia in their $\mathrm{ED}(83.2 \%, \mathrm{n}=124)$. Most respondents $(67.8 \%, \mathrm{n}=101)$ disagreed that nurses were sufficiently knowledgeable about nerve blocks (Figure A4 in Appendix).

To increase their use of regional anesthesia in the $\mathrm{ED}$, respondents indicated that they required more training $(76.5 \%, \mathrm{n}=114)$, a departmental protocol $(47.0 \%, \mathrm{n}=70)$, and more assistance from support staff $(30.2 \%, \mathrm{n}=45)$. Some respondents noted the need for a system that minimized disruption to ED patient flow $(13.0 \%, \mathrm{n}=19)$ and noted the need for a dedicated cart with necessary medications and echogenic needles (Figure 1). 


\section{DISCUSSION}

\section{Interpretation of findings}

Emergency physicians considered nerve blocks to be beneficial and safe and were interested in using regional anesthesia more frequently. However, most respondents said that to expand their use, they would require further training.

Enhancing emergency physician skills in ultrasoundguided regional anesthesia will facilitate its uptake in the ED. Only one-half of the respondents in our study reported being comfortable with ultrasound-guided regional anesthesia. Similarly, only $43 \%$ of ultrasound program directors in emergency medicine reported feeling comfortable with their skills. ${ }^{5}$ The inclusion of these techniques in core emergency ultrasound curricula will assist in closing this gap. ${ }^{4,7}$ Continuing medical education is required to support emergency physicians in learning new skills and also to supplement postgraduate emergency medicine training that increasingly includes regional anesthesia. Ultrasound fellows and emergency physicians with advanced training are well positioned to be champions of ultrasound-guided regional anesthesia and to facilitate the scale-up of this technique. Simulation has been well received in anesthesia education, including phantom gels, part-task trainers, virtual reality, and mannequins, and has led to improved block success, a shorter learning curve, and enhanced situational awareness. ${ }^{8}$

Respondents identified the time required and disruption of patient flow as additional barriers to use of regional anesthesia. This may be optimized by increased nursing staff knowledge of regional anesthesia and by employing departmental protocols. Nursing training should reflect familiarity with the equipment, procedure, and monitoring of patients. ${ }^{9}$ Akin to the use of ED procedural sedation protocols, the need for a regional anesthesia protocol in the ED has been described and should encompass patient screening for contraindications, a documentation process, a designated storage area for supplies, and interdepartmental agreements to avoid delays in communication. ${ }^{6}$

\section{Limitations}

Respondents comprised a convenience sample of elective members of a professional organization (CAEP), and academic centres were heavily represented. Respondents may comprise a subset of emergency physicians, particularly interested in regional anesthesia. A low response rate could have been improved with a pre-survey notification email, additional email reminders over a longer period, and the availability of incentives, strategies that have resulted in response rates of $20-30 \%{ }^{10}$

Our study included digital nerve blocks alongside other regional anesthesia. While digital nerve blocks are commonly performed in the ED, they are less complicated and typically not performed with ultrasound, thus not subject to the same barriers as other regional anesthesia. Last, consulting a biostatistician and survey design expert could have strengthened study design. ${ }^{10}$

\section{CONCLUSION}

Canadian emergency physicians engage in limited use of regional anesthesia but express an interest in expanding their use. While equipment is available, appropriate training and integration of these procedures into the departmental workflow is felt to be lacking. Additional training, departmental protocols, and expanded support from nursing staff are modifiable factors that physicians agreed would facilitate uptake of regional anesthesia in the ED.

Acknowledgements: This study was supported by the UHN Department of Emergency Medicine Research Grant.

Supplementary material: The supplementary material for this article can be found at https://doi.org/10.1017/cem.2020.51.

Competing interests: No conflicts of interest to declare.

\section{REFERENCES}

1. Wilson C. Feeling blocked? Another pain management tool in the emergency department. Ann Emerg Med 2018;72 (2):120-6.

2. Ritcey B, Pageau P, Woo MY, Perry JJ. Regional nerve blocks for hip and femoral neck fractures in the emergency department: A systematic review. CFEM 2016;18(1):37-47.

3. Stone MB, Wang R, Price DD. Ultrasound-guided supraclavicular brachial plexus nerve block vs procedural sedation for the treatment of upper extremity emergencies. Am 7 Emerg Med 2008;26(6):706-10.

4. Olszynski P, Kim D, Chenkin J, Rang L. The core emergency ultrasound curriculum project: A report from the Curriculum Working Group of the CAEP Emergency Ultrasound Committee. CFEM 2018;20(2):176-82.

5. Wilson CL, Chung K, Fong T. Challenges and variations in emergency medicine residency training of ultrasound-guided regional anesthesia techniques. AEM Educ Train 2017; $1(2): 158-64$. 
6. Amini R, Kartchner JZ, Nagdev A, Adhikari S. Ultrasoundguided nerve blocks in emergency medicine practice. 7 Ultrasound Med 2016;35(4):731-6.

7. Lewis D, Rang L, Kim D, et al. Recommendations for the use of point-of-care ultrasound (POCUS) by emergency physicians in Canada. CFEM 2019;21(6):721-6.

8. Kim TE, Tsui BC. Simulation-based ultrasound-guided regional anesthesia curriculum for anesthesiology residents. Korean 7 Anesthesiol 2019;72(1):13-23.
9. Russell RA, Burke K, Gattis K. Implementing a regional anesthesia block nurse team in the perianesthesia care unit increases patient safety and perioperative efficiency. $\mathcal{F}$ Perianesth Nurs 2013;28(1): 3-10.

10. Fernando SM, Cheung WJ, Choi SB, Thurgur L, Frank JR. Faculty mentorship during residency and professional development among practising emergency physicians. CFEM 2018;20(6):944-51. 